\title{
Efeitos diferenciados de práticas pedagógicas no aprendizado das habilidades de leitura ${ }^{1}$
}

Lúcia Helena Gazólis de Oliveira a,b Alicia Bonamino $^{c}$

\section{Resumo}

Este artigo discute a associação entre práticas pedagógicas declaradas pelos professores e o aprendizado de diferentes habilidades de leitura. Foram pesquisados aproximadamente 17 mil alunos e 600 professores do $2^{\circ}$ e do $3^{\circ}$ anos do ensino fundamental, utilizando-se Modelos Lineares Hierárquicos. A investigação mostrou efeitos diferenciados das práticas conforme o ano escolar e a habilidade em questão: no $2^{\circ}$ ano, o estilo de alfabetizar enfatizando sílabas e palavras descontextualizadas apresentou correlação negativa com o aprendizado do código de leitura e de localizar informações, enquanto a leitura silenciosa e em voz alta apresentou correlação positiva com o aprendizado dessas habilidades; no $3^{\circ}$ ano, a ênfase em cópia, ditado e caligrafia teve correlação negativa com o aprendizado de todas as habilidades investigadas e a leitura realizada pelo professor foi a prática que mais agregou conhecimento aos alunos entre todas as habilidades.

Palavras-chave: Habilidades de leitura. Efeitos de práticas de leitura. Escalas de leitura. Modelagem multinível.

\section{Introdução}

A recente universalização do ensino fundamental no Brasil e os avanços quanto ao monitoramento dos resultados escolares, promovido pelas avaliações nacionais e estaduais, intensificaram, no cenário educacional, o debate sobre os enormes desafios a serem enfrentados para que a garantia do acesso se faça acompanhar

\footnotetext{
a Pontifícia Universidade Católica do Rio de Janeiro - PUC-Rio. Rio de Janeiro, Rio de Janeiro, Brasil.

b Universidade Federal do Rio de Janeiro - UFRJ - Colégio de Aplicação - CAP. Rio de Janeiro, Rio de Janeiro, Brasil.

c Pontifícia Universidade Católica do Rio de Janeiro - PUC-Rio. Rio de Janeiro, Rio de Janeiro, Brasil.

${ }_{1}^{1}$ Pesquisa realizada na PUC-Rio no âmbito do Projeto Observatório da Educação/Edital 2010/Capes 
de uma educação de qualidade e, ainda, da transposição de obstáculos referentes à equidade. A concretização de uma boa escola para todos os alunos depende, em parte, de que os resultados das avaliações em larga escala transitem do diagnóstico para a interpretação dos fatores que influenciam o desempenho dos estudantes brasileiros e, assim, possam informar formuladores de políticas educacionais sobre as ações públicas prioritárias e orientar estratégias de ensino promotoras de aprendizagem nas escolas.

Este artigo tem o propósito de contribuir para a identificação dos fatores anteriormente mencionados, especialmente no que se refere ao aprendizado de Língua Portuguesa nas séries iniciais do ensino fundamental, bem como a duas das metas que vêm sendo monitoradas no âmbito do movimento "Todos pela Educação (TPE)" ". Trata-se da meta 2 - "Toda criança plenamente alfabetizada até os oito anos" - e da meta 3 - "Todo aluno com aprendizado adequado ao seu ano escolar".

O monitoramento dos resultados relacionados com a meta 2 tem ocorrido com base na Prova $\mathrm{ABC}^{2}$. A avaliação de 2012 revelou que o país não alcançou a meta esperada para 2010, ou seja, ter $80 \%$ dos alunos com aprendizado adequado até o final do $3^{\circ}$ ano do Ensino Fundamental. Os resultados mostraram que, em leitura, 44,5\% dos estudantes brasileiros concluintes dessa etapa escolar aprenderam o esperado, ou seja, o correspondente a 175 pontos na escala de

\footnotetext{
1 Todos Pela Educação' é um movimento da sociedade civil que tem a missão de contribuir para que até 2022, ano do bicentenário da Independência do Brasil, o país assegure a todas as crianças e todos os jovens o direito à Educação Básica de qualidade. Os objetivos do movimento são propiciar as condições de acesso, de alfabetização e de sucesso escolar, a ampliação de recursos investidos na Educação Básica e a melhora da gestão desses recursos. Esses objetivos foram traduzidos em 5 Metas, cuja evolução e alcance são monitorados de forma permanente, por meio da coleta de dados e da análise dos indicadores oficiais da Educação. São elas: Meta 1- Toda criança e todo jovem de 4 a 17 anos na escola; Meta 2- Toda criança plenamente alfabetizada até os 8 anos; Meta 3- Todo aluno com aprendizado adequado ao seu ano; Meta 4- Todo jovem de 19 anos com o Ensino Médio concluído, e Meta 5- Investimento em Educação ampliado e bem gerido. Por sua vez, o Decreto $N^{\circ}$ 6.094, de 24 de abril de 2007, do governo federal, dispõe sobre a implementação do Plano de Metas Compromisso Todos pela Educação, pela União, em regime de colaboração com Municípios, Distrito Federal e Estados, e a participação das famílias e da comunidade, mediante programas e ações de assistência técnica e financeira, visando à mobilização social pela melhoria da qualidade da educação básica. De acordo com o Art. $2^{\circ}$, a participação da União no Compromisso será pautada pela realização direta, quando couber, ou, nos demais casos, pelo incentivo e apoio à implementação, por Municípios, Distrito Federal, Estados e respectivos sistemas de ensino, de 28 diretrizes, entre as quais a de alfabetizar as crianças até, no máximo, os oito anos de idade, aferindo os resultados por exame periódico específico (Diretriz II). Em novembro de 2013, a Avaliação Nacional da Alfabetização (ANA) fez a primeira aferição nacional desses resultados.

${ }^{2}$ A prova $A B C$ teve sua segunda edição em 2012 e avaliou leitura, escrita e matemática. Foram avaliados 54 mil alunos de 1.200 escolas públicas e privadas, distribuídas em 600 municípios brasileiros. Metade da amostra é de alunos do $2^{\circ}$ ano e a outra metade, do $3^{\circ}$ ano, sendo, este último, considerado limite para a alfabetização, de acordo com o recém-lançado Pacto Nacional pela Alfabetização na Idade Certa (Pnaic). Ressalta-se que essa amostra ainda é reduzida e que a margem de erro padrão pode superar $5 \%$ em alguns casos.
} 
proficiência ${ }^{3}$. Em termos pedagógicos, somente a partir desse ponto, os alunos conseguem identificar temas de uma narrativa, localizar informações explícitas e identificar características de personagens em textos, como contos e histórias em quadrinhos. Considera-se que o percentual de 55,5\% dos alunos localizados na escala abaixo desse ponto ainda não atingiu níveis de leitura e de escrita suficientes para continuar a se apropriar dos conhecimentos previstos para os anos seguintes. É preciso salientar que há variações importantes entre regiões e redes de ensino quanto ao aprendizado dos alunos. Por exemplo, o melhor desempenho em escrita na prova $\mathrm{ABC}$ é o da Região Sudeste, com $65,6 \%$ dos alunos no nível adequado, enquanto o Nordeste, com $30,3 \%$, e o Norte, com $39,2 \%$, apresentaram os menores percentuais de alunos nesse mesmo nível. Em leitura, as Regiões Sul, com 64,6\%, e Centro-Oeste, com 64,1\%, apresentaram os melhores desempenhos, ficando novamente o Nordeste com o percentual mais baixo entre as regiões, com $42,5 \%$ dos estudantes em nível de aprendizagem considerado adequado (TODOS PELA EDUCAÇÃO, 2012b).

A meta 3, referente ao aprendizado adequado à série, tem sido monitorada por meio do Saeb/Prova Brasil ${ }^{4}$. A partir dos resultados da avaliação de 2005, foram realizadas projeções e estabelecidas metas para o nível de aprendizado dos alunos. Em relação ao $5^{\circ}$ ano do Ensino Fundamental, é esperado que, até o ano de $2022,70 \%$ dos alunos tenham desempenho superior ao nível de habilidades considerado adequado, ou seja, acima de 200 pontos na escala de proficiência de Língua Portuguesa do Saeb/Prova Brasil. Com base nessa meta de longo prazo, foram definidas metas intermediárias, que são acompanhadas sistematicamente. $\mathrm{O}$ ponto de corte para o estabelecimento das metas intermediárias foi determinado pelos percentuais de alunos que se encontravam acima/abaixo dos 200 pontos no ano de 2005. A Tabela 1 possibilita o acompanhamento da evolução desses indicadores.

Tomando-se o país como referência, constata-se que, em 2005, menos de $30 \%$ dos estudantes ultrapassavam os 200 pontos da escala de proficiência em Língua Portuguesa. Em termos pedagógicos, segundo Araújo e Luzio (2004), os estudantes com proficiências inferiores a esse patamar ainda não conseguem ler textos de diferentes gêneros e não superam o tratamento primário da leitura, localizando

\footnotetext{
${ }^{3}$ Resultados equalizados na escala do SAEB.

${ }^{4}$ A avaliação da Educação Básica nacional ocorre por meio de dois instrumentos. A Prova Brasil e o Saeb. A Prova Brasil é censitária para turmas de $5^{\circ}$ e $9^{\circ}$ anos das redes públicas das áreas urbana e rural, em escolas com mínimo de 20 alunos matriculados nos anos avaliados. O Saeb é amostral e contempla alunos do $5^{\circ} \mathrm{e}$ $9^{\circ}$ anos do Ensino Fundamental e do $3^{\circ}$ ano do Ensino Médio das redes pública e privada de todo o País, também nas áreas urbana e rural.
} 
Tabela 1 - Evolução dos indicadores de qualidade por região (Língua Portuguesa $5^{\circ}$ ano do EF)

\begin{tabular}{lcccccc}
\hline \multirow{2}{*}{$\begin{array}{c}\text { Brasil } \\
\text { Regiões }\end{array}$} & \multicolumn{6}{c}{ Porcentagem de alunos acima do nível adequado (200 pontos no Saeb) } \\
em comparação com as metas
\end{tabular}

Fonte: Elaboração própria a partir dos dados dos Relatórios De Olho nas Metas (TODOS PELA EDUCAÇÃO, 2008, 2010, 2012a).

* Meta.

** Abaixo da meta.

*** Meta alcançada.

apenas informações explícitas nos textos. Esses alunos não identificam o tema e a tese dos textos, a intencionalidade do uso de expressões e ainda não fazem inferências em escritos adequados à sua série.

Uma breve comparação entre as projeções e a evolução dos indicadores de qualidade evidencia que, embora a educação brasileira tenha avançado, considerando-se o aumento dos percentuais de alunos em níveis adequados de aprendizado ao longo do monitoramento, esse avanço não ocorreu na velocidade esperada. Enquanto a meta intermediária referente à Língua Portuguesa para o Brasil no ano de 2007 era de $29 \%$ dos alunos em níveis de habilidades superiores aos 200 pontos, o índice obtido foi de $27,9 \%$. Já em relação à meta de $2009,36,6 \%$, o país conseguiu alcançar 34,2\%. Em 2011, chega-se aos 40\% de estudantes em nível adequado de conhecimento, enquanto a meta estabelecida foi de 42,2\%. Entre as regiões, apenas as Regiões Sul e Centro-Oeste conseguiram superar as metas previstas para o referido ano. Nas demais, os índices não foram alcançados. Mesmo na região Sudeste, que ocupa a melhor posição em relação ao percentual de alunos em níveis adequados de habilidades, em 2011, apenas 50\% de alunos alcançaram esse patamar (TODOS PELA EDUCAÇÃO, 2008, 2010, 2012a).

Considerando-se a morosidade para alcançar as metas projetadas, bem como as desigualdades observadas e as evidências da literatura de que, para além das diferenças socioeconômicas, a escola pode alterar positivamente os resultados dos seus alunos (RUTTER et al., 1979; COTTON, 1995; SOARES, 2007), é razoável pensar que precisamos encontrar novas formas de atuação para a gestão 
da escola e das salas de aula. Assim, a presente investigação teve como objetivo compreender processos de aprendizagem e de ensino de forma a lançar pistas sobre decisões pedagógicas e políticas que possam indicar caminhos de intervenção.

\section{Amostra e instrumentos de pesquisa}

A subamostra em estudo refere-se aos resultados dos alunos do $2^{\circ}$ e do $3^{\circ}$ anos do ensino fundamental, obtidos pelo Estudo Longitudinal da Geração Escolar 2005GERES $^{5}$. No $2^{\circ}$ ano, foram investigados 17.628 alunos, distribuídos em 671 turmas, de 225 escolas. No $3^{\circ}$ ano, foram estudados 16.911 alunos, distribuídos em 632 turmas, de 228 escolas, pertencentes às redes municipal, estadual, federal e privada ${ }^{6}$, das cidades do Rio de Janeiro-RJ, de Belo Horizonte-MG, de Campinas-SP e de Campo Grande-MS. Quanto aos dados contextuais, a amostra corresponde aos professores de cada uma das turmas nos dois anos escolares abordados.

Os dados de caráter cognitivo foram coletados por meio dos testes de leitura que focalizam habilidades básicas tipicamente demandadas pela escola a alunos dos primeiros anos escolares. Em março de 2005, o teste mediu a proficiência prévia com que os alunos iniciaram o ano, condição indispensável para que se possam aferir, com maior rigor, as habilidades que foram desenvolvidas no decorrer de cada período letivo. No final do $2^{\circ}$ e do $3^{\circ}$ anos, em novembro de 2005 e de 2006, o GERES retornou às escolas para avaliar os mesmos alunos, verificando a aprendizagem escolar e o valor agregado pelas escolas.

Os dados contextuais foram coletados a partir das respostas dos professores ao questionário aplicado ao final de cada ano letivo e, portanto, do trabalho realizado junto às suas turmas do $2^{\circ}$ e do $3^{\circ}$ ano, cujos itens tratavam das práticas de alfabetização e de Língua Portuguesa ${ }^{7}$ declaradas pelos professores. Os questionários contextuais dos pais e dos alunos também foram utilizados

\footnotetext{
${ }^{5}$ O Estudo Longitudinal da Geração Escolar 2005 é uma pesquisa que coletou dados de leitura e de matemática de alunos do $2^{\circ}$ ao $5^{\circ}$ ano do ensino fundamental em cinco cidades brasileiras, no período de 2005 a 2008.

${ }^{6}$ Neste estudo, as redes estadual e municipal são referidas como escola pública e a redes privada e federal são referidas como escolas privadas. As escolas federais foram agrupadas à rede privada por possuírem características mais próximas a estas do que às escolas públicas.

7 Para os itens referentes às práticas de alfabetização, os professores dispunham das opções (A) ou (B). Uma das opções caracterizava práticas bastante representativas de uma alfabetização pautada no uso dos métodos fônico ou alfabético, e a outra opção caracterizava um estilo de prática que considerava também aspectos como a vivência dos alunos, o seu interesse e o uso de textos significativos. Quanto às práticas de Língua Portuguesa, os professores dispunham de opções que buscavam captar suas prioridades por meio da frequência de realização: várias vezes por semana, cerca de uma vez por semana, algumas vezes no bimestre, raramente ou nunca.
} 
nesta pesquisa e serviram para identificar o nível educacional e a profissão dos pais, bem como os objetos de consumo presentes na casa do aluno. Essas informações foram empregadas na confecção da variável do nível socioeconômico das famílias.

\section{Metodologia}

Na medida em que raramente é possível se chegar a uma variável complexa por meio apenas de uma pergunta efetuada aos respondentes, os itens dos questionários do professor foram utilizados na construção de escalas que reúnem vários itens, com o objetivo de se captarem conceitos latentes. De acordo com Babbie (2005), as escalas são dispositivos que reduzem os dados de forma que várias respostas podem ser resumidas em um único escore, mantendo-se os detalhes específicos daquelas respostas quase na totalidade.

Foram construídos dois grupos de escalas ${ }^{8}$. Um deles diz respeito aos itens respondidos pelos alunos nos testes. O outro grupo de escalas refere-se às práticas declaradas pelos professores.

No primeiro grupo, os itens cognitivos respondidos pelos alunos foram analisados e reunidos por meio de interpretação pedagógica e, em seguida, passaram por testes estatísticos ${ }^{9}$, que resultaram nas seguintes escalas de habilidades:

Processamento do código de Leitura - conjunto de itens que tratam do domínio da tecnologia da escrita: direção da escrita, identificação de sílabas, leitura de palavras, leitura de frases, separação de sílabas e composição de palavras.

Localização de informações explícitas - conjunto de itens que demandam a identificação de informações explícitas envolvendo apenas relações básicas, requerendo "retirar" informação de texto curto, com estrutura gramatical simples e recorrente no meio social ou no letramento escolar.

Integração de informações entre texto e contexto - conjunto de itens que implicam sentido de inferência, estabelecimento de relações entre partes do texto,

\footnotetext{
${ }^{8}$ O processo de construção das escalas está disponível em: http://www.maxwell.lambda.ele.puc-rio. br/21591/21591_1.PDF

9 Todos os testes foram realizados no programa MSP (MokkenScale for Polythomous Itens) de Molenaar e Sjistma (2000). As respostas ao conjunto de itens foram examinadas quanto a escalonabilidade e confiabilidade, por meio do ajuste da escala de Mokken, da teoria da resposta ao item não paramétrica.
} 
identificação do que é relevante (tema, tese e conflito da narrativa, relações de causa e consequência), compreensão quanto aos elementos de coesão, coerência, anáfora e percepção da organização sequencial da narrativa.

Apreensão de aspectos discursivos dos textos - conjunto de itens que demandam compreensão sobre informações do contexto, marcadas pela relação entre texto e situação comunicativa, reveladas a partir da percepção de aspectos como o propósito de um texto, os efeitos de humor e de ironia, o objetivo do uso de onomatopeias, a adequação da linguagem formal e informal, e as características de alguns gêneros textuais.

Em relação ao $2^{\circ}$ ano, só houve itens suficientes para construção das escalas de Processamento e Localização. Já para o $3^{\circ}$ ano, só não foi possível manter a escala de Processamento. Essa variação das escalas está relacionada às próprias especificidades do que é ensinado em cada ano escolar.

Já no segundo grupo, os itens respondidos pelos professores, também analisados pedagogicamente e por parâmetros estatísticos, resultaram nas seguintes escalas: Estilo menos contextualizado de alfabetizar; Estilo mais contextualizado de alfabetizar; Leitura realizada pelo professor para os alunos; Leitura silenciosa realizada pelos alunos; Leitura em voz alta realizada pelos alunos; Atividades de cópia, ditado e caligrafia.

Quanto aos resultados, os itens testados para medir o Estilo de alfabetizar formaram escalas com boas propriedades, mostrando forte nível de correlação (estilo menos contextualizado: $\mathrm{H}=0,62 /$ estilo mais contextualizado: $\mathrm{H}=0,52$ ) e uma forte confiabilidade para essa medida ( $\mathrm{Rho}=0,80$ e 0,96 , respectivamente) ${ }^{10}$.

As escalas de Leitura realizada pelo professor, Leitura silenciosa realizada pelo aluno e Leitura em voz alta realizada pelo aluno apresentaram coeficientes fortes para a escalonabilidade dos itens, indicando uma alta associação entre estes $(\mathrm{Hs}=0,91$; 0,$68 ; 0,74$, respectivamente) e, também, altos coeficientes para a confiabilidade da medida $(0,92 ; 0,88 ; 0,84$, respectivamente). A escala obtida para Cópia, ditado e caligrafia apresentou coeficientes medianos tanto para a escalonabilidade quanto para a confiabilidade $(\mathrm{H}=0,48$ e $\mathrm{Rho}=0,65$, respectivamente).

\footnotetext{
${ }^{10}$ Parâmetros de escalonabilidade ( $\mathrm{H}$ de Loevinger): Entre 0,5 e 1=forte; entre 0,4 e 0,5=médio; entre 0,3 e $0,4=$ discreto; menor que $0,3=$ sem escalonabilidade. Parâmetros de confiabilidade (Rho de Mokken): Acima de $0,7=$ forte; entre 0,6 e 0,7=média; menor que 0,6=fraca.
} 
As escalas de habilidades em Leitura apresentaram resultados estatísticos menos expressivos. Ainda assim, com exceção de uma escala (Aspectos discursivos, no $2^{\circ}$ ano $)^{11}$, os coeficientes de escalonabilidade apresentaram valores entre $0,44 \mathrm{e}$ 0,20 , e os coeficientes de confiabilidade, valores entre 0,82 e 0,42 . Esses valores abrangem escalas fortes, médias e fracas. No entanto, como o que se pretende é compreender as relações que ocorrem entre o ensino e a aprendizagem, e não ordenar os indivíduos para qualquer tipo de classificação, foram admitidos coeficientes menores.

A partir da obtenção das escalas, foram construídos Modelos Hierárquicos Lineares (HLM) para a associação entre as práticas enfatizadas pelos professores e o aprendizado de habilidades de leitura pelos estudantes. A modelagem multinível é apropriada ao estudo de dados distribuídos não aleatoriamente ou agrupados em diferentes níveis hierárquicos, como é o caso dos dados educacionais, segundo os quais os alunos estão agrupados em turmas, as turmas em escolas e as escolas em redes de ensino, por exemplo.

No caso desta pesquisa, para mensurar o efeito professor, utilizamos um modelo de dois níveis: aluno e turma.

Para efeitos de manipulação dos dados no HLM, todas as variáveis, quantitativas e contínuas, foram padronizadas, de modo a possuírem média igual a zero e desvio padrão de uma unidade, o que permite padronizar a interpretação dos resultados das diversas regressões.

A seguir, estão as Equações 1 e 2 do modelo estimado para medir a associação entre a proficiência em processamento apurada no final do $2^{\circ}$ ano (variável dependente) e as práticas declaradas pelos professores, com os devidos controles (variáveis explicativas). Para todas as variáveis dependentes (Processamento, Localização, Integração e Aspectos discursivos) os modelos estimados seguem o mesmo padrão.

\section{Level-1 Model}

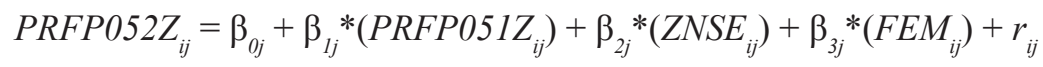

\footnotetext{
${ }^{11}$ Essa escala obteve $\mathrm{H}=0,13$; porém quando utilizada nos modelos, não apresentou nenhum resultado que destoasse dos demais.
} 
Level-2 Model

$$
\begin{aligned}
& \beta_{0 j}=\gamma_{00}+\gamma_{01}{ }^{*}\left(\text { PARTIC }_{j}\right)+\gamma_{02}{ }^{*}\left(\text { ZALFTRO5 }_{j}\right)+\gamma_{03}{ }^{*}\left(\text { ZLERPO5 }_{j}\right)+ \\
& \gamma_{04}{ }^{*}\left(Z L E R S 05_{j}\right) \\
& +\gamma_{05}^{*}(\text { ZLERV05 })+\gamma_{06} *\left(Z E S C P T 05_{j}\right)+u_{0 j} \\
& \beta_{l j}=\gamma_{10}+u_{l j} \\
& \beta_{2 j}=\gamma_{20} \\
& \beta_{3 j}=\gamma_{30}
\end{aligned}
$$

No nível 1 (Aluno),

$P R F P 052 Z_{i j}$ corresponde à nota, padronizada, em processamento, no final do $2^{\circ}$ ano, referente ao aluno $i$ da turma $j$;

$P R F P 051 Z_{i j}$ corresponde à nota padronizada do mesmo aluno no teste realizado no início do $2^{\circ}$ ano (controle);

$Z N S E_{i j}$ é o índice socioeconômico padronizado do aluno;

FEM é uma variável dicotômica indicadora do gênero feminino ( $1=$ feminino e $0=$ masculino) $r$ é o erro da regressão, ou seja, a diferença entre o valor real da variável dependente e o seu respectivo valor previsto pelo modelo.

No nível 2 (Turma),

PARTIC é uma variável dicotômica indicadora da rede em que o aluno está matriculado ( $0=$ rede pública; $1=$ rede privada);

ZALFTR05 $5_{j}$ é a variável padronizada que representa o estilo menos contextualizado de alfabetizar do professor da turma $j$ no $2^{\circ}$ ano;

ZLERP05 ${ }_{j}$ é a variável padronizada relacionada à prática de leitura em voz alta na turma $j$ no $2^{\circ}$ ano;

ZLERSO5 jé a variável padronizada relacionada à prática de leitura silenciosa na turma $j$ no $2^{\circ}$ ano; $Z L E R V 05_{j}$ é a variável padronizada relacionada à prática de leitura em voz alta na turma $j$ no $2^{\circ}$ ano;

ZESCPT05 ${ }_{j}$ é a variável padronizada relacionada à prática de cópia, ditado e caligrafia na turma $j$ no $2^{\circ}$ ano;

$u$ é o erro da regressão associado à turma $j$.

\section{Apresentação e discussão dos resultados}

A seguir, na Tabela 2, são apresentados os resultados dos modelos estimados, que representam a relação entre as práticas de Língua Portuguesa desenvolvidas pelos professores participantes da pesquisa e o aprendizado dos seus alunos em relação às diferentes habilidades de leitura. 
Tabela 2 - Resultados dos modelos estimados

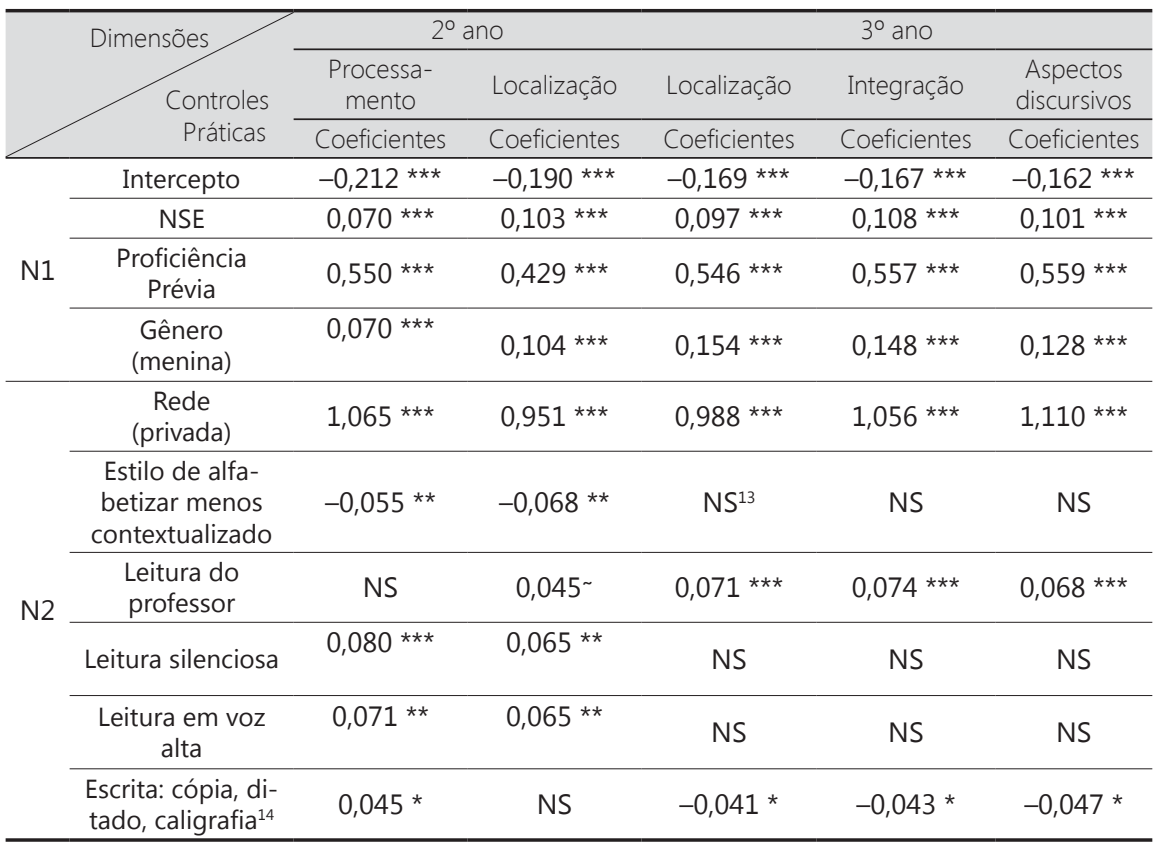

Fonte: Os autores (2014).

*** p-valor $<0,001$.

** $\mathrm{p}$-valor $<0,01$.

* p-valor $<0,05$

$\sim$ p-valor $<0,1$.

Assim como foi necessária a padronização das variáveis, será preciso também apresentar os resultados em termos de desvios padrão. Esse procedimento é essencial para que os diferentes resultados possam ser comparados.

Conforme largamente apontado pela literatura, as variáveis de controle empregadas nesta pesquisa (nível socioeconômico, proficiência prévia, gênero e rede) evidenciaram que os seus efeitos estão associados à aprendizagem escolar, confirmando a importância da sua utilização para separá-los dos efeitos específicos das práticas de leitura.

\footnotetext{
${ }^{12}$ Algumas práticas não apresentaram significância estatística, o que está sinalizado como NS (Não significativo). Esse resultado não deve ser interpretado como uma inadequação dessas práticas para o ensino da leitura, mas como a ausência de informação sobre seus efeitos, nesta amostra especificamente.

${ }^{13} \mathrm{~A}$ ausência de práticas menos restritas de escrita, como, por exemplo, a produção de texto, deve-se apenas ao fato de não ter sido possível a formação de escalas que as incluíssem, tendo em vista os critérios estatísticos estabelecidos.
} 
Observa-se que todos os coeficientes tiveram significância estatística de 99\% de confiança, ou seja, $1 \%$ de chance de que os resultados tenham sido obtidos ao acaso.

O nível socioeconômico mostrou correlação positiva com o aprendizado e seus coeficientes foram estimados entre 0,07 e 0,1 , indicando que, a cada unidade de desvio padrão a mais que os alunos obtiveram nesse índice, os resultados finais se fizeram acompanhar, em média, de um aumento entre 7\% e 10\% do desvio padrão da escala de proficiência.

O efeito do gênero sobre a aprendizagem apresentou magnitude semelhante ao efeito do nível socioeconômico, mas sua interpretação é de outra ordem, em razão de se tratar de uma variável dicotômica. Os resultados mostraram que as meninas alcançaram média de desempenho superior a dos meninos em todas as dimensões de leitura. No caso, por exemplo, em que a variável apresentou o coeficiente mais alto (Localização de informação, no $3^{\circ}$ ano), as meninas apresentam, em média, a vantagem de $15 \%$ de um desvio padrão em relação aos meninos.

Uma variável que costuma mostrar elevada correlação com os resultados dos alunos é a dos seus próprios resultados anteriores. Esse fato ocorre porque, tendo-se a proficiência prévia como controle, o efeito das demais variáveis se restringe a uma determinada janela de tempo, o que é bastante apropriado para se verificarem efeitos educacionais. Os resultados encontrados evidenciaram que o acréscimo de uma unidade de desvio padrão na proficiência prévia acarreta um acréscimo em torno de 50\% na proficiência alcançada ao final de cada ano escolar, em todas as dimensões de leitura investigadas.

Finalmente, a variável de controle de maior associação com a variável dependente foi a rede de ensino frequentada pelo aluno (privada ou pública). $O$ fato de estudar na rede privada proporcionou aos alunos uma vantagem em torno de um desvio padrão nas quatro dimensões do aprendizado de leitura, em comparação com os alunos que estudaram em escolas públicas (coeficientes entre 0,95 e 1,11).

Depois de filtrados os efeitos das variáveis de controle, é possível observar qual foi a parcela de contribuição das variáveis explicativas, ou seja, das práticas de Língua Portuguesa, na variação restante nos dados.

No $2^{\circ}$ ano, quanto ao Processamento do código de leitura, das quatro modalidades para as quais os resultados apresentaram significância estatística, três destas estão 
associadas positivamente com a habilidade de Processamento em leitura, enquanto uma delas tem correlação negativa com esse aprendizado. Mais especificamente, as práticas de Leitura silenciosa e de Leitura em voz alta, e o conjunto de práticas de Cópia, ditado e caligrafia contribuíram para o aumento da proficiência dos alunos no que diz respeito ao aprendizado do código alfabético. Já o Estilo menos contextualizado de alfabetizar está associado a um impacto negativo em relação ao aprendizado do código alfabético. Especificando-se ainda mais esses resultados, a cada unidade de desvio padrão a mais obtida pelo professor em prática de Leitura silenciosa, seus alunos tiveram, em média, um ganho de $8 \%$ de um desvio padrão na proficiência em Processamento, com confiabilidade de 99,9\%. Da mesma forma, o aumento de uma unidade no desvio padrão na prática de Leitura em voz alta proporcionou, em média, um aumento de 7,1\% de um desvio padrão na proficiência dos alunos em Processamento, com confiabilidade de $99 \%$. Em relação às práticas de Cópia, ditado e caligrafia, quando um professor apresentou uma unidade a mais de desvio padrão nessas práticas, ele contribuiu para um aumento médio do aprendizado do código alfabético dos seus alunos de $4,5 \%$ de desvio padrão, com confiabilidade de $95 \%$. Inversamente aos resultados anteriores, cada unidade a mais no desvio padrão, relacionada a professores que apresentam um estilo menos contextualizado para alfabetizar, está associada a um impacto negativo no aprendizado de seus alunos em Processamento do código de leitura, da ordem, em média, de 5,5\%.

Com relação à habilidade de Localizar informações explícitas nos textos, ainda no $2^{\circ}$ ano, o estilo menos contextualizado de alfabetizar também está associado a um menor aprendizado por parte dos alunos. Esse resultado tem confiabilidade de $99 \%$, como ocorreu em relação ao aprendizado do código alfabético, sendo que o valor do coeficiente $(-0,068)$ indica maiores prejuízos para o aprendizado. $\mathrm{O}$ aumento de uma unidade de desvio padrão relativo ao Estilo menos contextualizado de alfabetizar se faz acompanhar, em média, de 6,8\% de um desvio padrão a menos no desenvolvimento da habilidade de Localizar informações.

Por sua vez, a prática mais intensa de leitura, tanto da Leitura silenciosa quanto da Leitura em voz alta, corresponde a aumentos estatisticamente significantes da proficiência em Localização de informações ( $99 \%$ de confiabilidade). A cada unidade de desvio padrão apresentada a mais pelo professor para essas práticas, observa-se um acréscimo de $6,5 \%$ do desvio padrão nas notas dos alunos. Os coeficientes obtidos para essas práticas quanto ao aprendizado de Localização de informações mostraram uma pequena queda em relação aos obtidos para o aprendizado de Processamento do código. No entanto, a prática de Leitura 
realizada pelo professor, que não havia apresentado significância estatística para Processamento, passa a explicar, também, a proficiência em Localização. Ainda que com uma significância estatística menor do que a das demais variáveis ( $90 \%$ de confiabilidade), o coeficiente mostra um acréscimo de $4,5 \%$ do desvio padrão na proficiência em Localização, em média, a cada unidade de desvio padrão a mais, correspondente à prática de ler para os alunos.

Nos modelos estimados para o $3^{\circ}$ ano, duas práticas apresentaram significância estatística para todas as variáveis dependentes. Uma delas está associada positivamente com o aprendizado e a outra, ao contrário, tem impacto negativo na proficiência dos alunos. A prática de ler para os alunos apresentou elevada confiabilidade $(99,9 \%)$ em relação a todos os modelos. O seu impacto é importante e semelhante, em termos de magnitude, para todas as diferentes habilidades de leitura. Nota-se que essa modalidade de prática tem um impacto especial no $3^{\circ}$ ano. A cada unidade de desvio padrão a mais que o professor apresentou em relação a ler para os seus alunos, ele contribuiu, em média, com um aumento em torno de $7 \%$ de um desvio padrão para o aprendizado de cada uma das habilidades de leitura.

No que diz respeito à prática de Cópia, ditado e caligrafia, apesar de os coeficientes e de a significância estatística serem mais baixos ( $95 \%$ de confiabilidade), seus efeitos se estendem de forma semelhante a todas as habilidades de leitura. No entanto, o sentido da relação com a proficiência é inverso ao da prática de Leitura realizada pelo professor. Quanto mais o professor enfatizou as práticas de Cópia, ditado e caligrafia, menos os seus alunos desenvolveram as habilidades de Localização, Integração e de apreensão de Aspectos discursivos. O aumento de uma unidade do desvio padrão dessas práticas se fez acompanhar, em média, de $4 \%$ a menos de um desvio padrão no aprendizado de cada habilidade de leitura.

Antes da discussão propriamente dita dos resultados, tornam-se necessárias algumas considerações sobre a sua magnitude. Em educação, é comum que os resultados sejam interpretados como demasiadamente pequenos. No entanto, a magnitude dos dados educacionais deve ser interpretada dando-se muita atenção ao contexto. No caso deste estudo, tal interpretação deve considerar os seguintes aspectos: (i) que a parcela do efeito professor para o resultado dos alunos costuma variar entre $7 \%$ e $21 \%$, sendo que as demais variações relacionam-se com fatores extraescolares; (ii) que, enquanto algumas práticas demonstraram associação positiva com o aprendizado, outras demonstraram associação negativa e que apenas essa constatação já é de grande valia para uma priorização entre as 
práticas; (iii) que o efeito apresentado por cada uma das práticas investigadas diz respeito apenas a uma das modalidades de leitura que o professor pode trabalhar; (iv) que as práticas não são excludentes, pois podem e devem ser trabalhadas em conjunto; (v) que os efeitos das práticas, neste estudo, foram subdivididos por habilidades, sendo, portanto, importante que seja levado em conta o seu efeito geral para o aprendizado.

Feitas essas considerações, passamos a analisar o efeito das práticas de Língua Portuguesa na habilidade de Processamento do código alfabético para os alunos do $2^{\circ}$ ano.

Como já mencionamos, a opção por um ensino da língua pautado prioritariamente em letras e/ou sílabas (denominado, neste trabalho, como Estilo menos contextualizado de alfabetizar) esteve associada a um menor aprendizado por parte dos alunos. Já as práticas de Leitura silenciosa e de Leitura em voz alta contribuíram de forma positiva e equivalente para o aprendizado do código alfabético.

Os resultados obtidos para o Estilo menos contextualizado de alfabetizar e para as práticas de Leitura silenciosa e Leitura em voz alta, quando correlacionados, apresentam uma lógica complementar. Ao mesmo tempo em que o enfoque em letras e/ou sílabas isoladas correspondeu ao menor aprendizado, a utilização de textos para leitura nas duas modalidades, silenciosa e voz alta, demonstrou contribuir positivamente para o aprendizado, sendo que os efeitos dessas duas práticas estão entre os mais altos alcançados em todos os modelos. Para que se tenha uma dimensão melhor desse resultado, podemos compará-lo ao de outra variável, como, por exemplo, a que mede o nível socioeconômico (NSE). Ou seja, o efeito das práticas de Leitura silenciosa e de Leitura em voz alta foi tão importante para explicar os resultados dos alunos quanto o NSE, que é um fator consensualmente considerado de grande impacto no aprendizado escolar.

Esse resultado contraria uma visão muito comum entre os professores de que só é válido, ou mesmo possível, propor a leitura de textos aos alunos quando eles tiverem dominado a leitura de sílabas e de palavras isoladas, o que supõe uma concepção na qual o conhecimento é adquirido de forma linear e gradativa.

Contrapondo-se a prática de leitura por meio de sílabas descontextualizadas com a prática de leitura de textos, ainda que não seja possível identificar pelo questionário aplicado aos professores os gêneros e tipos de textos utilizados, pode-se 
atribuir o resultado obtido à diferenciação quanto ao grau de contextualização oportunizado por ambas as práticas.

A prática de alfabetizar considerada neste estudo como menos contextualizada caracteriza-se pelo ensino inicial das letras, depois das sílabas e, por último, das palavras e frases. Esse estilo de alfabetizar remete, segundo Weisz (1990), a uma concepção, segundo a qual, para aprender a ler basta aprender um código de transcrição da fala, ou seja, o aluno estabelece associações entre fonemas e grafemas, memoriza essas associações e, por meio de mecanismos de análises e sínteses, as utiliza para ler e para escrever. Silva (1999) também identifica entre os professores a concepção de que ler é dar respostas a sinais gráficos. Segundo ele, nesse caso, o texto é o estímulo e a leitura, a resposta. Ou o leitor erra ou o leitor acerta. Essa visão de aprendizagem está sintonizada com o entendimento de que os alunos só poderão lidar com textos quando tiverem vencido etapas anteriores. Como os alunos "ou acertam ou erram", não existe espaço para aprendizagens ainda em processo, ou seja, cuja solução não corresponda ao produto final esperado. Esses princípios de ensino-aprendizagem terminam por impossibilitar qualquer forma de contextualização e significado, uma vez que são vistos como obstáculos para os alunos, tornando a leitura um ato de pura decodificação. Sendo assim, quanto mais o professor demonstrou ser adepto a práticas menos contextualizadas de alfabetização, mais lento foi o aprendizado dos seus alunos quanto ao processamento do código alfabético, como pode ser inferido a partir dos dados ${ }^{14}$.

Os resultados obtidos nesta pesquisa apontam na direção inversa, indicando que, no $2^{\circ}$ ano, quando os alunos ainda estão em fase de apropriação do código alfabético, as práticas de leitura são altamente recomendáveis. Essa é uma implicação pedagógica importante, visto que as frequências obtidas pela pesquisa em relação às práticas de leitura no $2^{\mathrm{o}} \mathrm{ano}^{15}$ foram muito baixas, sendo provável que esse perfil se repita em outros contextos. Os poucos professores que enfatizaram as práticas de Leitura silenciosa e de Leitura em voz alta, no ano considerado adequado para a alfabetização, produziram o maior efeito positivo encontrado por este estudo nos resultados dos seus alunos. Ainda que os dados não permitam uma identificação pormenorizada das práticas desses professores, os mesmos se referem à utilização de uma diversidade de práticas para as duas modalidades de leitura. Nesse sentido, os resultados reforçam as indicações de

\footnotetext{
${ }^{14}$ Essa análise está relacionada apenas com as práticas que se limitam ao trabalho de justaposição das unidades da língua e, de forma alguma, ao trabalho com a consciência fonológica.

${ }^{15}$ As frequências não foram apresentadas devido às limitações de tamanho do artigo.
} 
estudos ${ }^{16}$ que enfatizam a necessidade de uma intensa relação dos alunos com os textos e de que o ensino do código alfabético deva acontecer de forma integrada com as práticas de letramento.

Estendendo-se a análise para a habilidade de Localização, observa-se a manutenção do sentido da correlação. Os sinais dos coeficientes permaneceram os mesmos obtidos para o Processamento, reforçando, assim, tanto a associação negativa entre as práticas menos contextualizadas de alfabetizar e a habilidade de Localização de informações, quanto a associação positiva entre as práticas de Leitura silenciosa e em voz alta, e a proficiência nessa habilidade. Esse resultado não surpreende: como os alunos aprenderam menos o código alfabético, menor foi sua autonomia para a leitura de textos nos quais precisavam buscar uma informação, ainda que explícita. Do ponto de vista pedagógico, este resultado pode ainda implicar em que, se os alunos aprendem menos devido a uma prática descontextualizada de alfabetização e, por esse motivo, não avançam para a habilidade de localizar, o professor continue a enfatizar o tipo de prática que julga ser a melhor no momento inicial de alfabetização, aumentando a chance de defasagem em relação ao aprendizado da leitura.

Comparando-se o efeito das práticas de leitura no aprendizado do Processamento e da Localização de informações, identificamos um resultado que pode parecer curioso: as práticas de Leitura silenciosa e de Leitura em voz alta apresentaram coeficientes mais altos para o aprendizado do código do que para o aprendizado de Localização de informações. Neste caso, parece que os coeficientes mais altos para as práticas de Leitura silenciosa e de Leitura em voz alta em relação à habilidade de Processamento estão captando uma diferença, normalmente expressiva nos resultados dos alunos, entre não conseguir ler e passar a ler. Em outras palavras, quanto menos um aluno sabe, mais conhecimento ele pode agregar e o fato de passar a atribuir sentido ao texto representa um grande salto em termos de proficiência, o que se reflete no aumento dos coeficientes.

Considerando-se o conjunto de argumentos utilizados para explicar as diferenças entre os coeficientes alcançados pelas práticas de Leitura silenciosa e de Leitura em voz alta, e entre as habilidades de Processamento e Localização no $2^{\circ}$ ano, ressaltamos que os resultados reforçam a ideia de que ler é ainda mais relevante quando "não se sabe ler". Uma implicação pedagógica importante decorrente é a de que, ao que tudo indica, os professores deveriam introduzir as práticas de leitura mais cedo em suas salas de aula. Há fortes evidências de que quanto

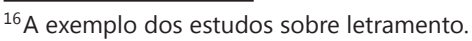


mais cedo a leitura acontece na escola, melhores serão os resultados dos alunos. Conforme Magda Soares (2009), é preciso reconhecer que o acesso inicial à língua escrita não se reduz a aprender a ler e escrever, no sentido de aprender a grafar e a decodificar palavras, isto é, não se reduz à alfabetização no sentido que é atribuído a essa palavra. É parte integrante e principal do acesso ao mundo da escrita, mesmo do acesso inicial a esse mundo, aprender a fazer uso da leitura. Sendo assim, esperamos que os resultados apresentados anteriormente possam contribuir para desfazer um círculo vicioso comum na educação: o aluno não lê porque não sabe ler e não aprende a ler porque não lê.

Quanto aos resultados obtidos para as práticas de Cópia, ditado e caligrafia, estes apresentaram correlação positiva para o aprendizado de Processamento no $2^{\circ}$ ano e correlação negativa para as habilidades de Localização, Integração e Apreensão de aspectos discursivos, no $3^{\circ}$ ano. Tal fato parece indicar que as práticas em questão podem cumprir um papel no momento de aquisição do código alfabético, mas não se justificam num momento posterior, quando as habilidades esperadas para um bom desempenho do aluno dizem respeito à compreensão mais ampla de textos. Avalia-se que o efeito positivo das práticas de Cópia, ditado e caligrafia, na habilidade de Processamento, no $2^{\circ}$ ano, esteja relacionado com o foco central dos alunos em análises reflexivas sobre a constituição do código alfabético, nesse momento da escolaridade. Além disso, a pesquisa contatou que o trabalho dos professores no $2^{\circ}$ ano esteve extremamente voltado para a escrita: o percentual de professores que declarou realizar a prática de leitura silenciosa várias vezes por semana foi de apenas $2,2 \%$, enquanto a prática de caligrafia obteve percentual de $21,4 \%$. Assim, em um contexto no qual praticamente não se trabalha a leitura, mas, ao contrário, a prioridade é dada às práticas de escrita, as oportunidades para os alunos pensarem sobre a constituição do código podem ter ocorrido nos momentos de cópia, ditado e caligrafia.

Quanto ao $3^{\circ}$ ano de escolaridade, duas das práticas investigadas apresentaram resultados significativos: a Leitura realizada pelo professor para os alunos e as práticas de Cópia, ditado e caligrafia. A Leitura realizada pelo professor para os seus alunos, leitura de histórias ou outros textos, apresentou correlação positiva com o aprendizado e foi a modalidade de prática de leitura que se manteve significativa e com potencial para agregar conhecimento aos alunos em um número mais variado de habilidades. O efeito dessa prática já começa a aparecer na habilidade de Localização no $2^{\circ}$ ano, com resultados modestos, afirmando-se no $3^{\circ}$ ano, quando apresenta um forte impacto, comparável ao efeito que o NSE apresenta para Processamento no $2^{\circ}$ ano, por exemplo. Ler para os alunos 
contribuiu com um efeito semelhante para que eles aprendessem a Localizar informações, a Integrar informações e a identificar Aspectos discursivos dos textos. Esse resultado é coerente com o fato de que, quando o professor lê, a ênfase pedagógica recai sobre a compreensão ampla do texto.

Já a priorização da Cópia, do ditado e da caligrafia, contrariamente ao resultado obtido para o $2^{\circ}$ ano, apresentou correlação negativa com o aprendizado dos alunos do $3^{\circ}$ ano, tanto em Localização e Integração de informações quanto na Apreensão de aspectos discursivos dos textos. No caso do $3^{\circ}$ ano, a pesquisa constatou um incremento nas práticas de leitura, apesar de os percentuais terem se mantido consideráveis para as práticas de Cópia, ditado e caligrafia. Além de os alunos terem tido mais oportunidades de ler no $3^{\circ}$ ano, contribui para esse resultado o fato de que as reflexões próprias do processamento do código alfabético não são mais tão centrais nesse ano escolar. Sendo assim, do fato de as práticas docentes continuarem a enfatizar a cópia, o ditado e a caligrafia, em detrimento de outras mais eficazes, como é o caso da leitura silenciosa, por exemplo, decorre um efeito negativo nos resultados dos alunos.

\section{Conclusão}

A análise realizada em relação ao ensino e à aprendizagem da alfabetização e do letramento, baseada em dados longitudinais, na construção de escalas de habilidades dos alunos e de práticas pedagógicas dos professores, assim como no uso de modelos multiníveis, permite afirmar a existência de efeitos diferenciados das práticas docentes, conforme o ano escolar e a habilidade avaliada. A construção das escalas de habilidades de leitura evidenciou a existência de quatro subdimensões, a saber: Processamento do código alfabético, Localização de informações explícitas, Integração de informações e Apreensão de aspectos discursivos dos textos.

Entre os principais resultados, encontramos que, no $2^{\circ}$ ano, o estilo de alfabetizar enfatizando sílabas e palavras descontextualizadas teve efeito negativo no aprendizado do código da leitura e da localização de informações. Já as práticas de leitura silenciosa e em voz alta tiveram efeito positivo sobre o aprendizado dessas mesmas habilidades. Encontramos, também, que as atividades de cópia, ditado e caligrafia apresentam efeito positivo no $2^{\circ}$ ano, apenas no que diz respeito à aquisição do código alfabético. No $3^{\circ}$ ano, a ênfase do professor em cópia, ditado e caligrafia apresentou um efeito negativo no aprendizado do conjunto de habilidades de leitura, ao passo que a leitura de histórias e outros tipos de texto 
realizada pelo professor para os alunos foi a prática que teve efeito positivo na maior parte das habilidades investigadas.

Em termos de implicações pedagógicas, podemos concluir que as práticas de alfabetização não deveriam priorizar o ensino de letras e sílabas isoladamente, e que as práticas de leitura silenciosa e em voz alta são altamente recomendáveis para o ensino das habilidades de apropriação do código alfabético e, consequentemente, de localização de informações explícitas nos textos. Ou seja, esse resultado em particular indica que os professores deveriam introduzir práticas de leitura, para e pelos alunos, o mais cedo possível em suas salas de aula.

\section{Referências}

ARAÚJO, C. H.; LUZIO, N. Leitura na educação básica. Brasília: Inep, 2004. Disponível em $<$ http://www.inep.gov.br/imprensa/artigos/leitura.htm $>$. Acesso em: 4 fev. 2012.

BABBIE, E. Métodos de pesquisa de Survey. Belo Horizonte: Editora UFMG, 2005. p. 213-243.

COTTON, K. Effective schooling practices: a research synthesis 1995 update. The Northwest Regional Educational Laboratory, 1995. Disponível em: <http:// frank.mtsu.edu/ jhausler/Effective_Schooling_Practices.htm>.

RUTTER, M. et al. Fifteen thousand hours: secondary schools and their effects on children. London: Open Books, 1979.

SILVA, E. T. Concepções de leitura e suas consequências no ensino. Revista Perspectiva, Florianópolis, v. 17, n. 31, p. 11-19, 1999.

SOARES, J. F. O efeito da escola no desempenho cognitivo dos seus alunos. Cadernos de Pesquisa, São Paulo, v. 37, n. 130, p. 492-517, 2007.

SOARES, M. Alfabetização e letramento na educação infantil. Revista Pátio: Educação Infantil, Porto Alegre, v. 7, n. 20, 2009. 
TODOS PELA EDUCAÇÃO - TPE. Primeiro relatório de acompanhamento das cinco Metas do movimento Todos Pela Educação, 2008. Disponível em: $<$ http://www.todospelaeducacao.org.br//arquivos/biblioteca/1a60588b-054d4422-9a4f-0f009d7b2039.pdf>. Acesso em: 28 mar. 2015.

. De Olho nas Metas 2010: Relatório de acompanhamento das cinco metas do Todos Pela Educação, 2010. Disponível em: $<$ http://www.todospelaeducacao. org.br//arquivos/biblioteca/sumario_de_olho_nas_metas_2010_pdf\% $\% 28$ final $\% 29$. pdf $>$. Acesso em: 28 mar. 2015.

. Relatório De Olho nas Metas 2012: Quinto relatório de acompanhamento das cinco metas do Todos Pela Educação, 2012a. Disponível em: $<$ http://www. todospelaeducacao.org.br//arquivos/biblioteca/de_olho_nas_metas_2012.pdf $>$. Acesso em: 28 mar. 2015.

. Relatório De olho nas Metas: especial prova ABC, 2012b. Disponível em: $<$ http://www.todospelaeducacao.org.br//arquivos/biblioteca/prova_abc.pdf $>$. Acesso em: 28 mar. 2015.

WEISZ, T. As contribuições da psicogênese da língua escrita e algumas reflexões sobre a prática educativa de alfabetização. In: SÃO PAULO (Estado). Secretaria de Educação. Ciclo básico de jornada única: uma nova concepção do trabalho pedagógico. São Paulo: SE/CENP, 1990.

\section{Differentiated effects of pedagogical practices on the learning of reading abilities Abstract}

This article discusses the association between teaching practices declared by teachers and their students'learning of different reading skills. Approximately 600 teachers and 17,000 $2^{\text {nd }}$ and $3^{\text {rd }}$ grade elementary school students were investigated in this longitudinal study, using Hierarchical Linear Models. The research showed different effects of pedagogical practices according to the students' grade and the ability in question: in 2nd grade, the alphabetization style emphasizing decontextualized syllables and words showed a negative correlation with the reading code learning and the skill of locating information in a text, while silent and aloud reading showed a positive correlation with learning these skills; in 3rd grade, the emphasis in copy, dictation and calligraphy activities 
showed a negative correlation with the learning of all skills researched, and reading performed by teachers was the practice that most added knowledge to students among all skills.

Keywords: Reading abilities. Effects of reading practices. Reading scale. Multilevel modeling.

\section{Efectos diferenciados de las prácticas educativas en el aprendizaje de habilidades de lectura Resumen}

Este artículo analiza la relación entre las prácticas de enseñanza reportadas por maestros y el aprendizaje de habilidades de lectura. Fueron investigados aproximadamente 17.000 estudiantes y 600 profesores, en el $2^{\circ}$ y $3^{\circ}$ año de enseñanza primaria, utilizando Modelos Lineales Jerárquicos. La investigación mostró efectos diferenciados de las prácticas pedagógicas de acuerdo con el año escolar y la habilidad enseñada: en el $2^{\circ}$ año, el estilo de alfabetización que enfatiza sílabas y palabras descontextualizadas mostró correlación negativa con el aprendizaje del código de lectura y con la localización de información, mientras que la práctica de lectura silenciosa y en voz alta mostró una correlación positiva con el aprendizaje de estas habilidades; en el $3^{\circ}$ año, el énfasis en copia, dictado y caligrafía presentó correlación negativa con el aprendizaje de todas las habilidades investigadas y la lectura realizada por el maestro fue la práctica que agregó más conocimiento a los alumnos en todas las habilidades.

Palabras clave: Habilidades de lectura. Efectos de las prácticas de lectura. Escalas de lectura. Modelado multinivel.

\section{Informações sobre as autoras}

Lucia Helena Gazólis de Oliveira: Doutorado em Educação. Contato: lhgazolis@oi.com.br

Alicia Bolamino: Doutorado em Educação. Contato: aliciambonamino@gmail.com 